\title{
COMPARAÇÃO DO CRESCIMENTO E DESENVOLVIMENTO DA ALFACE (Lactuca sativa L.) NO INTERIOR E NO EXTERIOR DE UMA ESTUFA DE POLIETILENO EM SANTA MARIA, RS
}

\section{COMPARISON OF GROWTH AND DEVELOPMENT OF LETTÜCE PLANS (Lactuca sativa L..) INSIDE AND OUTSIDE OF A POLYETHYLENE GREENHOUSE IN SANTA MARIA, RS}

\author{
Jorge Frederico Orellana Segovia $^{1}$ Jerônimo Luís Andriolo ${ }^{2}$ Galileo Adeli Buriol ${ }^{2}$ \\ Flávio Miguel Schneider ${ }^{3}$
}

RESUMO

O trabalho teve por objetivo comparar o crescimento e o desenvolvimento das cultivares de alface Brasil202, White Boston e Regina, no interior e no exterior de uma estufa de polietileno durante o período de inverno em Santa Maria. A estufa permitiu um ganho térmico favorável ao crescimento da alface, da ordem de 256 graus-dia acima da temperatura base de crescimento de $10^{\circ} \mathrm{C}$, durante o período de 50 dias. A temperatura do solo também foi mais favorável no interior da estufa, $5,3^{\circ} \mathrm{C}$ em média, em relação ao exterior. As plantas cultivadas no interior da estufa apresentaram curvas de crescimento similares àquelas cultivadas no exterior, porém com valores mais elevados dos parâmetros de crescimento de área foliar, massa verde da parte aérea, massa seca das folhas, do caule e das raízes. A relação parte aérea/sistema radiador também foi mais elevada no interior da estufa. $O$ número de folhas por planta foi similar nos dois ambientes. Dentre as três cultivares testadas, a Brasil-202 apresentou maior precocidade e maior acumulação de massa seca. A estufa de polietileno mostrou ser uma alternativa eficiente para a produção de alface nos meses de inverno.

Palavras-chave: alface, Lactuca sativa L., crescimento, desenvolvimento, cultivo protegido.

\section{SUMMARY}

Growth and development of lettuce cultivar Brasil202, White Boston and Regina inside and outside of a polyethylene greenhouse were compared in Santa Maria, RS. During a winter period of50 days the greenhouse caused an increase in about 256 degree-days in the temperature values above the base temperature for growth (estimated in $10^{\circ} \mathrm{C}$ ). Mean soil temperature was also $5.3^{\circ} \mathrm{C}$ higher inside the greenhouse. The growth patterns of plants cultivated inside the greenhouse were similar to those cultivated outside. Growth parameters of leaf surface, shoot fresh weight, dry weight of leaves. stem and roots and the shoot/root ratio were lower outside the greenhouse. The number of leaves per plant was similar in both conditions. Brasil-202 showed earlier growth and higher dry matter accumulation. Protection of plants with polyethylene greenhouses is an efficient technique to improve lettuce crop production in winter.

Key words: Lettuce, Lactuca sativa L., growth, development, protected cultivation.

\section{INTRODUÇÃO}

A alface (Lactuca sativa L.) é uma hortaliça de grande importância econômica no Sul do Brasil. O seu cultivo ao longo do ano passa por dois períodos com condições meteorológicas pouco favoráveis. O primeiro ocorre nos meses de inverno, devido às baixas temperaturas (inferiores a $10^{\circ} \mathrm{C}$ ) e precipitações pluviométricas prolongadas que retardam o crescimento e danificam as plantas. O segundo período desfavorável ocorre no verão, provocado pelas elevadas temperaturas do ar (acima de $20^{\circ} \mathrm{C}$ ) e pela elevada intensidade da radiação solar, que favorecem sobretudo o pendoamento precoce das plantas. $\mathrm{Na}$

\footnotetext{
${ }^{1}$ Engenheiro Agrônomo, Mestre, Pesquisador da EMBRAPA/CPAF, Amapá.

${ }^{2}$ Engenheiro Agrônomo, Doutor, Professor, Departamento de Fitotecnia, Centro de Ciências Rurais (CCR), Universidade Federal de Santa Maria (UFSM), 97105-900, Santa Maria - RS. Autor para correspondência: BURIOL.

${ }^{3}$ Engenheiro Agrônomo, Mestre, Professor, Departamento de Fitotecnia, CCR, UFSM.
} 
região de Santa Maria, a ocorrência das temperaturas mínimas prejudiciais é mais frequente durante o inverno mas pode ocorrer também no final do outono e no início da primavera (ESTEFANEL $\boldsymbol{e t}$ al., 1978).

As temperaturas do ar mais favoráveis ao crescimento e produção de plantas de alface de boa qualidade situam-se entre 15 e $24^{\circ} \mathrm{C}$, sendo a mínima de $7^{\circ} \mathrm{C}$ (KNOTT, 1962). No Brasil, BRUNINI et al. (1976) determinaram a temperatura base de crescimento da alface cultivar White Boston, sendo de $6^{\circ} \mathrm{C}$ para o sub-período germinaçãotransplante e de $10^{\circ} \mathrm{C}$ para o sub-período transplante-colheita.

Uma das alternativas atualmente existente para minimizar o efeito negativo das baixas temperaturas no período de inverno, consiste na proteção ambiental com túneis ou estufas cobertas com filmes de polietileno. Essa técnica vem se expandindo rapidamente no Sul do Brasil. Pesquisas realizadas em Santa Maria mostram que os túneis e as estufas propiciam um ganho térmico tanto nas temperaturas do ar como do solo (BURIOL et al., 1993a, 1993b; SCHNEIDER et al,, 1993). O cultivo da alface nesses ambientes surge, portanto, como uma das alternativas para obter maior regularidade na sua produção no Sul do País.

O presente trabalho tem por objetivo comparar o crescimento e o desenvolvimento de três cultivares de alface durante o inverno, no interior de uma estufa de polietileno localizada em Santa Maria, RS.

\section{MATERIAIS E MÉTODOS}

Os ensaios foram realizados no Campo Experimental do Departamento de Fitotecnia da Universidade Federal de Santa Maria, no interior e no exterior de uma estufa tipo capela com $25 \mathrm{~m}$ de comprimento, $10 \mathrm{~m}$ largura e 3,5m de altura máxima, coberta com polietileno transparente de 100(i de espessura. O preparo do solo nos dois ambientes foi realizado de maneira convencional e a adubação de acordo com os resultados da análise do solo. O transplante foi efetuado em 07/08/1989 quando as plântulas apresentavam 4 a 5 folhas definitivas, no espaçamento de $0,25 \mathrm{~m}$ entre plantas e entre linhas. Durante o período de duração do experimento a irrigação foi realizada sempre que a tensão da água do solo atingia valores entre $-0,4$ a $-0,6$ bar.

As três cultivares utilizadas foram a Brasil202, White Boston e Regina, dispostas em um delineamento experimental de blocos casualizados com cinco repetições e $1,75 \mathrm{~m}^{2}$ por parcela. A cada sete dias, durante o transcorrer do período experimental, foram coletadas quatro plantas por parcela. Imediatamente após cada coleta, determinou-se a massa verde da parte aérea $\left(\mathrm{MF}_{\mathrm{a}}\right)$, o número de folhas maiores que $1,5 \mathrm{~cm}$ de comprimento por planta (NF) e a área foliar (AF) de cada uma das plantas pelo método dos discos. Após, o material vegetal foi submetido, a secagem em estufa $\left(65^{\circ} \mathrm{C}\right.$ durante 72 horas) para a determinação da massa seca das folhas $\left(\mathrm{MS}_{\mathrm{f}}\right)$, do caule $\left(\mathrm{MS}_{\mathrm{c}}\right)$ e do sistema radicular $\left(\mathrm{MS}_{\mathrm{r}}\right)$. Os dados obtidos foram utilizados para calcular o índice de área foliar (IAF), a taxa de produção de massa seca da parte aérea $\left(\mathrm{TPMS}_{\mathrm{r}}\right)$ e do sistema radicular $\left(\mathrm{TPMS}_{\mathrm{a}}\right)$ e a relação parte aérea/sistema radicular (RPA/SR) (LUCHESI, 1984).

A caracterização do ambiente no interior e no exterior da estufa foi feita pela medida das temperaturas do ar e do solo e da umidade reativa do ar. As medidas da temperatura e umidade do ar no interior da estufa foram realizadas com o auxilio de um termohigrógrafo instalado dentro de um abrigo meteororólogico localizado na parte central da estufa e a 1,20m acima do nível do solo. A temperatura do solo foi medida com geotermômetro instalado também na parte central da estufa e a $5 \mathrm{~cm}$ de profundidade. No ambiente externo esses elementos foram obtidos junto a estação meteorológica do Departamento de Fitotecnia da UFSM, localizada à aproximadamente $100 \mathrm{~m}$ da estufa. Calculou-se a média diária das temperaturas do ar e do solo e da umidade reativa do ar à partir dos valores medidos às $9 \mathrm{~h}, 15 \mathrm{~h}$ e $21 \mathrm{~h}$. A partir da temperatura média diária, calculou-se os graus-dia e a soma acumulada dos mesmos durante o período experimental. Os graus-dia foram determinados subtraindo-se a temperatura base de crescimento igual a $10^{\circ} \mathrm{C}$ da temperatura média diária.

A análise dos resultados foi feita em duas etapas. Na primeira, comparou-se o parâmetro biológico obtidos nos dois ambientes na última coleta realizado, com as três cultivares confundidas. A seguir comparou-se as três cultivares, com os dois ambientes confundidos. A significância das médias foi testada pelo teste de Tukey a 5\% de probabilidade. Na segunda etapa, analisou-e a evolução de cada um dos parâmetros de crescimento (cultivares confundidas) e desenvolvimento ao longo do período experimental. Para facilitar a visualização das relações, curvas foram ajustadas a partir dos valores médios de cada um dos parâmetros.

\section{RESULTADOS E DISCUSSÃO}

Os valores diários das temperaturas máximas e mínimas do ar foram mais elevados no interior da estufa (Figura 1). Entretanto, a diferença entre as temperaturas máximas nos dois ambientes foi maior 


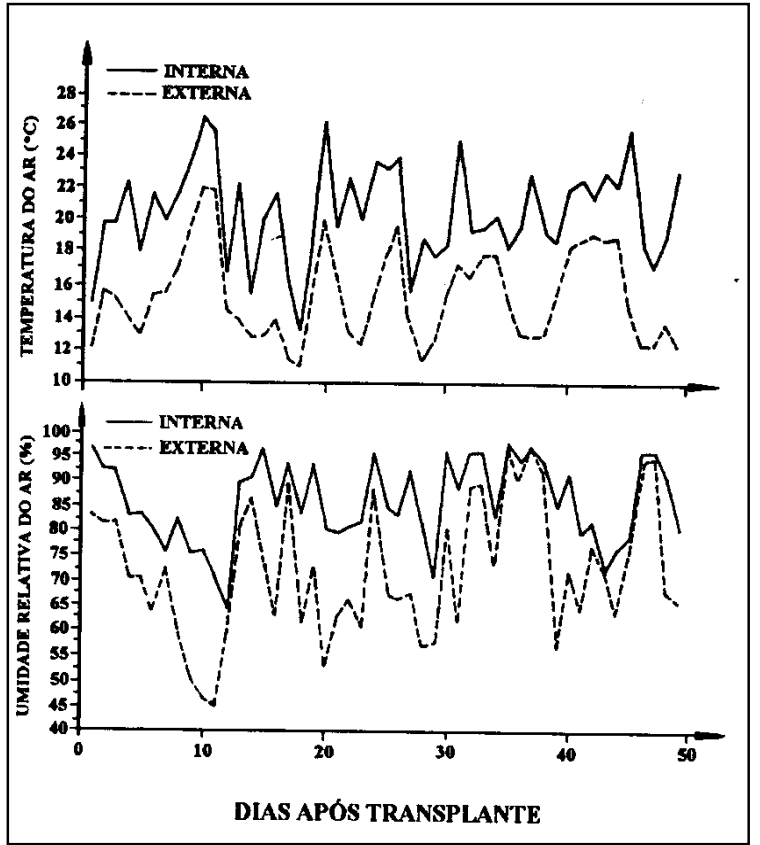

Figura 1 - Média diária da temperatura e umidade relativa do ar no interior e exterior da estufa ao longo do período experimental. Santa Maria, RS, 1989.

do que entre as mínimas. Considerando a temperatura base de crescimento da alface de $10^{\circ} \mathrm{C}$, a soma térmica no período do experimento foi de 256 graus-dia superior no interior da estufa em relação ao exterior. Os valores médios diários da umidade relativa do ar também foram superiores no interior da estufa. Porém, contrariamente ao que foi observada com a temperatura do ar, a diferença entre os valores máximos foi menor do que a diferença entre os valores mínimos diários. A temperatura média diária do solo a $5 \mathrm{~cm}$ de profundidade foi de $22,0^{\circ} \mathrm{C}$ no interior e de $16,7^{\circ} \mathrm{C}$ no exterior.
A comparação dos parâmetros de crescimento e desenvolvimento nos dois ambientes mostrou diferenças significativamente superiores no interior da estufa, com exceção da taxa de produção de massa seca da parte aérea (TPMS) (Tabela 1). Quando os ambientes são confundidos e as cultivares comparadas entre si, observa-se que a cultivar Brasil-202 apresentou um crescimento da parte aérea (MF, e MS,) e também um desenvolvimento (NF) significativamente superior às outras duas cultivares. A menor área foliar (IAF) foi observada na cultivar Regina (Tabela 2).

A evolução dos parâmetros de crescimento e desenvolvimento no interior e no exterior da estufa durante o período estudado (Figura 2 a-h), mostra que o número de folhas emitidas (Figura 2a) tende a um aumento mais rápido no interior da estufa. Por outro lado, a acumulação de massa seca (Figura 2b) nos dois ambientes mostra uma velocidade semelhante, embora com valores mais baixos no exterior. O mesmo comportamento é observado em relação a acumulação de massa seca foliar (Figura 2c), no período anterior aos 42 dias do transplante. Após esse período, uma nítida diferença na velocidade de crescimento do caule (Figura 2d) é constatada no interior da estufa. $\mathrm{O}$ crescimento das raízes (Figura 2e) passa a ser maior no interior da estufa a partir de aproximadamente 21 dias após o transplante. A taxa diária de produção de massa seca (Figura 2f) no interior da estufa se mostra nitidamente deslocada para a esquerda e decresce a partir de aproximadamente 40 dias após o transplante. O índice de área foliar (Figura 2g) mostra uma tendência semelhante ao crescimento em massa seca das folhas (Figura 2c), porém a amplitude da diferença é maior. A relação entre a parte aérea e o sistema radicular (Figura 2h) se mostra mais elevada no interior da estufa.

Tabela 1 - Médias do número de folhas por planta (NF), índice de área foliar (IAF), razão parte aérea sistema radicular (PA/SR), massa fresca da parte aérea (Mfa), massa seca das folhas (Msf), caule (Msc) sistema radicular (Msr) massa seca total da planta (Mst) e taxa diária de produção de massa seca (TPMS).

\begin{tabular}{|c|c|c|c|c|c|c|c|c|c|}
\hline Ambiente & $\mathrm{NF}$ & IAF & PA/SR & Mfa & $\mathrm{MSr}$ & MSc & Msr & MSt & TPMS \\
\hline Interior & $28,20 a^{*}$ & $3,23 a$ & $9,86 \mathrm{a}$ & $170,00 \mathrm{a}$ & $4,71 \mathrm{a}$ & $0,53 \mathrm{a}$ & $0,45 \mathrm{a}$ & $5,67 \mathrm{a}$ & $4,06 \mathrm{a}$ \\
\hline Exterior & $21,40 \mathrm{~b}$ & $2,03 \mathrm{~b}$ & $8,11 \mathrm{~b}$ & $105,50 \mathrm{~b}$ & $3,64 b$ & $0,31 b$ & $0,39 \mathrm{~b}$ & $4,34 b$ & $3,69 a$ \\
\hline
\end{tabular}

\footnotetext{
* Ambiente com média não seguida da mesma letra difere significativamente pelo teste de Tukey em 5\% de probabilidade.
} 
Tabela 2 - Médias do número de folhas por planta (NF), índice de área foliar (IAF), massa fresca da parte aérea $\left(\mathrm{MF}_{\mathrm{a}}\right)$, massa seca das folhas $\left(\mathrm{MF}_{\mathrm{f}}\right)$, caule $\left(\mathrm{MS}_{\mathrm{c}}\right)$, sistema radicular $\left(\mathrm{MS}_{\mathrm{r}}\right)$, massa seca total da planta $\left(\mathrm{MS}_{\mathrm{t}}\right)$, razão parte aérea/sistema radicular das três cultivares de alface.

\begin{tabular}{lcccccccc}
\hline Cultivar & $\mathrm{NF}$ & $\mathrm{IAF}$ & $\mathrm{MF}_{\mathrm{a}}$ & $\mathrm{MF}_{\mathrm{f}}$ & $\mathrm{MS}_{\mathrm{c}}$ & $\mathrm{MS}_{\mathrm{r}}$ & $\mathrm{MS}_{\mathrm{t}}$ & $\begin{array}{c}\mathrm{RPA} / \mathrm{S} \\
\mathrm{R}\end{array}$ \\
& & & & & & & & \\
\hline Brasil-202 & $25,50 \mathrm{a} *$ & $2,89 \mathrm{a}$ & $157,50 \mathrm{a}$ & $4,68 \mathrm{a}$ & $0,44 \mathrm{a}$ & $0,43 \mathrm{a}$ & $5,56 \mathrm{a}$ & $9,90 \mathrm{a}$ \\
White Boston & $24,30 \mathrm{a}$ & $2,64 \mathrm{a}$ & $138,12 \mathrm{~b}$ & $4,16 \mathrm{~b}$ & $0,38 \mathrm{~b}$ & $0,44 \mathrm{a}$ & $4,99 \mathrm{~b}$ & $8,20 \mathrm{~b}$ \\
Regina & $24,5 \mathrm{~b}$ & $2,36 \mathrm{~b}$ & $112,50 \mathrm{c}$ & $3,67 \mathrm{c}$ & $0,43 \mathrm{a}$ & $0,37 \mathrm{~b}$ & $4,48 \mathrm{c}$ & $8,70 \mathrm{~b}$
\end{tabular}

*Cultivar com média não seguida da mesma letra difere significativamente pelo teste de Tukey em $5 \%$ de probabilidade.

determinado pelo número de folhas emitidas mostra uma tendência semelhante durante todo o período experimental (Figura 3a). Porém, a cultivar Regina apresentou uma velocidade de crescimento mais baixa do que as outras duas cultivares, no período após os 21 dias do transplante.

Os resultados apresentados mostraram que as plantas de alface
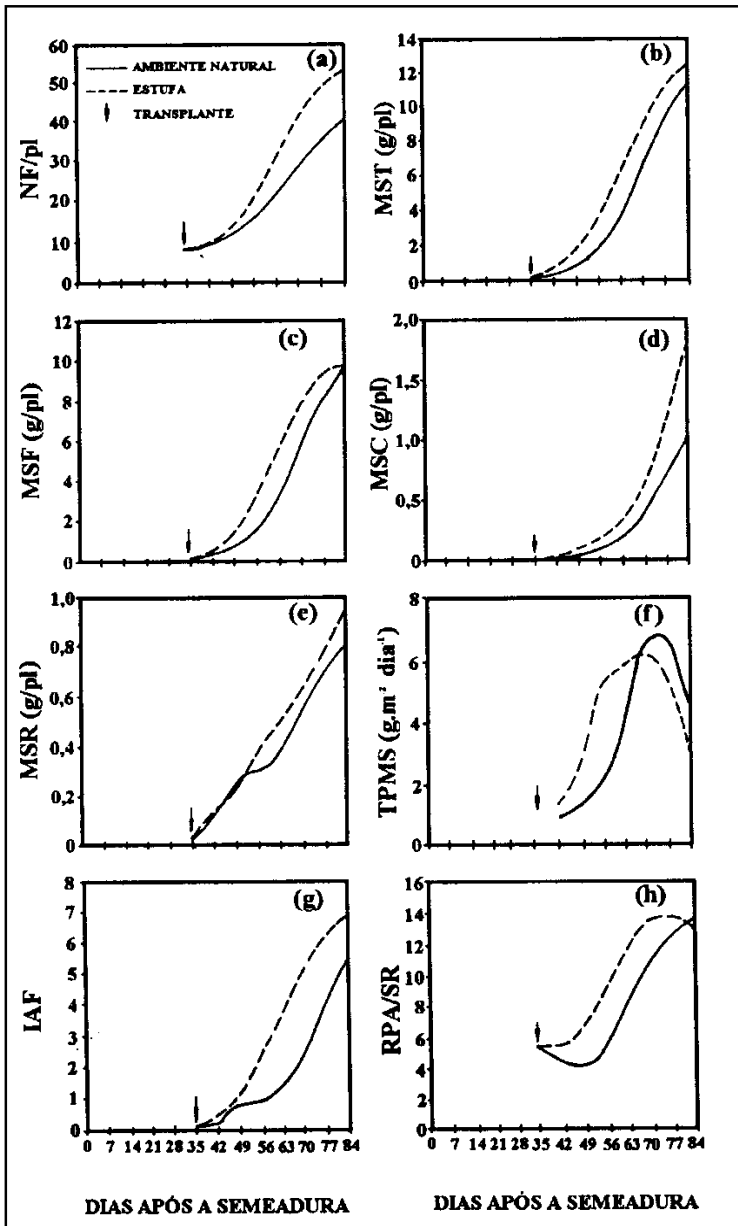

Figura 2 - Número de folhas (NF) por planta, massa seca total $\left(\mathrm{MS}_{\mathrm{T}}\right)$, do caule $\left(\mathrm{MS}_{\mathrm{C}}\right)$ e das raízes $\left(\mathrm{MS}_{\mathrm{R}}\right)$ por planta, taxa de produção de massa seca (TPMS), índice de área foliar (IAF) e razão parte aérea/sistema radicular (RPA/SR). Valores médios das três cultivares durante o período experimental, no interior e no exterior da estufa. Santa Maria, RS, 1989. cultivadas no interior de estufa apresentaram uma taxa de crescimento maior. Isso significa que é possível obter uma produção mais precoce e de melhor qualidade do que aquela obtida com o cultivo tradicional em ambiente não protegido. Os resultados indicaram também que existem diferenças no comportamento das diferentes cultivares em ambiente protegido. A explicação para o comportamento diferenciado das cultivares está relacionada provavelmente com a grande amplitude térmica diária ocorrida nas estufas. As temperaturas do ar no interior da estufa atingiram valores elevados durante o dia, que se situaram dentro dos limites considerados étimos ao crescimento da alface. Entretanto, as temperaturas mínimas do ar situaram-se abaixo da temperatura ótima de crescimento. As temperaturas noturnas influenciam fortemente os fenômenos fisiológicos como a taxa respiratória, o transporte dos assimilados e a absorção hídrica e mineral. As plantas que se adaptam às baixas temperaturas noturnas se caracterizam pela capacidade de manter uma atividade fisiológica intensa dentro de limites térmicos mais amplos. A cultivar Regina, por ter sido selecionada

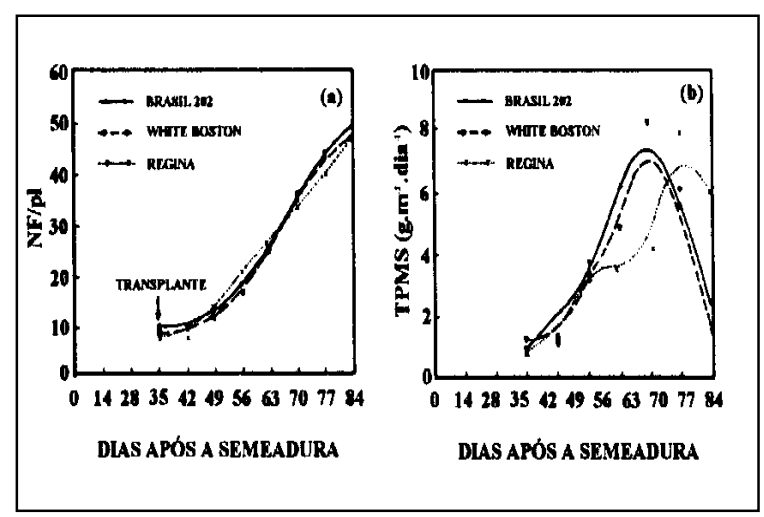

Figura 3 - Relação entre o número de folhas (NF) por planta e o número de dias após o transplante (a) e evolução da taxa de produção de massa seca (TPMS) (b) no interior e no exterior da estufa. Santa Maria, RS, 1989.

Ciência Rural, v. 27, n. 1, 1997. 
para regiões com temperaturas elevadas, se mostrou um material pouco adaptado ao cultivo durante o inverno.

A evolução dos parâmetros de crescimento e desenvolvimento mostra que o efeito da estufa se exerce, sobretudo sobre a velocidade de crescimento da planta. A ação da temperatura sobre o crescimento dos vegetais é um fenômeno conhecido (CORNILLON \& BOUDON, 1979; MEYER et al., 1983, OH et al., 1989). Os resultados apresentados confirmam essa dependência. Porém, a análise do crescimento das folhas, caule e raízes mostram que a temperatura influencia os diferentes órgãos da planta de maneira distinta durante o período de desenvolvimento. Assim, é o caule que passa a receber uma parcela importante da biomassa total da planta após aproximadamente 40 dias do transplante, em detrimento da folhas. Essa constatação sugere que o ponto ideal de colheita da alface se situa antes do crescimento máximo da planta durante a fase vegetativa, uma vez que somente as folhas têm valor comercial.

A amplitude observada entre as valores das curvas obtidas no interior e no exterior da estufa para os parâmetros da massa seca foliar (Figura 2c) e do índice de área foliar (Figura $2 \mathrm{~g}$ ) indica que a massa específica das folhas é menor no interior da estufa. Isso significa que nesse ambiente as folhas se expandem mais rapidamente. Esse fato pode ser atribuído principalmente aos teores mais elevados da umidade reativa do ar que existem na estufa durante o nictêmero (TIBBITS \& BOTTEMBERG, 1976). Essa característica favorece a apresentação visual do produto, mas é negativa do ponto de vista da resistência ao transporte e da conservação póscolheita. Um melhor manejo da umidade do ar e principalmente do solo no interior das estufas no período pré-colheita se toma então recomendável a fim de aumentar a resistência das folhas.

Os resultados indicam que a estufa é uma alternativa eficiente para obter uma maior regularidade de produção da alface nos meses de inverno no Sul do Brasil. Permite obter uma produção mais precoce sob um ciclo curto de cultura (50 dias) sendo uma boa opção como cultura intercalar entre dois ciclos consecutivos de culturas de maior valor económico, como por exemplo o tomateiro.

\section{AGRADECIMENTOS}

Os autores agradecem ao Engenheiro Agrônomo Raimundo Parente de Oliveira, Pesquisador da EMBRAPA/CPAF-Amapá, pelo auxílio prestado no ajustamento das curvas de tendência dos parâmetros de crescimento e desenvolvimento das plantas.

\section{REFERÊNCIAS BIBILIOGRÁFICAS}

BRUNINI, O, LÍSBÃO, R.S, BERNARDI, J.B. $\boldsymbol{e} \boldsymbol{t} \boldsymbol{a l}$. Temperatura base para alface (Lactuca sativa L.) cultivar White Boston, em um sistema de umidade térmico. Revista de Olericultura, Lavras, v. 16, p. 28-29, 1976.

BURIOL, G. A., SCHNEIDER, F.M., ESTEFANEL, V. $\boldsymbol{e} \boldsymbol{t}$ al Modificação da temperatura mínima do ar causada por estufas de polietileno transparente de baixa densidade. Rev Brás Agrometerol, Santa Maria, v. 1, n.1, p. 43-49, 1993a

BURIOL, G. A., STRECK, N.A., SCHENEIDER, F. M., et al Modificação ambiental causada por túneis baixos de polietileno transparente perfurado cultivados com alface. Ciência Rural, Santa Maria, v. 23, n. 3, p. 261-266, 1993 b.

CORNILLON, P., BOUDON, M. Influence de Ia température dês racines sur Ia croissance dês laitues et dês tomates. Ineidenee sur Ia composition lipidique. Ann Agron, Paris, v. 30, n. 5, p. $431-442,1979$.

ESTEFANEL, V., BURIOL, G.A., SACCOL, A.V., et al. Variabilidade e probabilidade de ocorrência de temperaturas mínimas absolutas do ar no Estado do Rio Grande do Sul. Rev Centro de Ciências Rurais, Santa Maria, v. 8, n. 4, p. 363-384, 1978.

KNOTT, J.E. Handbook for vegetable grovers. 2. ed. New York: John Wiley \& Sons, 1962. 245 p.

LUCHESI, A.A. Utilização prática da análise de crescimento vegetal. Anais da Escola Superior de Agricultura Luiz de Queiroz, São Paulo, v. 41, p. 181-202, 1984.

MEYER, B.S., ANDERSON, D.B., BOHNING, R.H., et al. Introdução à fisiologia vegetal. 2. ed. Lisboa: Fundação Calouste Gulbenkian, 1983. 710 p.

OH, J.Y., HOSHINO, K., NONAKA, M., et al. Physiologieal and ecological studies on cold hardiness ofiettuce II. The effect of cold stress ofcold stress at different growth stages ofiettuce. Hortic Abst, East Mailing, v. 59, n.2, p. 122, 1989,

SCHNEIDER, F.M., BURIOL, G.A., ANDRIOLO, J.L., et al Modificação na temperatura do solo causada por estufas de polietileno de baixa densidade em Santa Maria, RS. Rev Brás Agrometeorol, Santa Maria, v. 1, n. 1, p. 37-42, 1993.

TIBBITS, T.W., BOTTEMBERG, G. Growth of lettuce under controiled humidity leveis. J Amer Soe Hortic Sei, Mount Vernon, v. 101, n. 1, p. 70-73, 1976. 